Bohemia. He studied medicine at Prague under Count William Macneven, whose Irish forbears accompanied James II to the Continent in 1689 and became landowners in Bohemia. Count William was director of medical studies in the University of Prague and took a prominent part in supporting the incipient Czech cultural revival during the era of 'enlightened absolutism' under Joseph II. Through Macneven, Mikan, who had become a practitioner at the spa of Teplice, was appointed professor of botany and chemistry at the university in 1775 . This post he held for thirty-seven years, lecturing and carrying out research. He re-established proper courses of instruction and made it obligatory for students to qualify in both chemistry and botany as well as in their other subjects. In order to secure proficiency Mikan established the first chemical laboratory in Prague in 1784 and also laid out a botanic garden that is still in existence. The laboratory was a primitive affair adapted from a store-house of the original Carolinum, but it enabled him and his assistants to undertake the first analyses of many Czech spa and thermal waters.

After 1792 'enlightened absolutism' gave place to the 'reactionary absolutism' that lasted until 1848 and under which science was not encouraged. Not until 1810 were more commodious laboratories put at Mikan's disposal, and such progress as he was able to make was achieved in the face of much opposition, although a few progressive nobles gave him and his students encouragement and financial aid. Mikan was thrice dean of the medical faculty (there was no science faculty until much later) and was for many years vice-director of studies. When he retired in 1811 two appointments were made. His son, Jan Kristian Mikan, who had previously acted as his assistant, became professor of botany, and $J$. Freysmuth was appointed lecturer in chemistry. At this time there were no contemporary scientific publications in Czech; so that Mikan's writings are all in German and his name is usually rendered $J$. Gottfried Mikan. His work was, nevertheless, of vital importance for the advancement of science among the Czech nation.

\section{Finance and Social Service in Great Britain}

The recent Political and Economic Planning (P E P) broadsheet "Fair Shares for All" (No. 192) is a fitting counterpart to that issued earlier in the year under the title "Financial Mysticism" (No. 188). The latter made a useful contribution to lucid thinking about five simple questions : the financing of the War; the risk of national bankruptcy; the value of 'warship weeks' ; export policy ; and the repayment of the National Debt. In regard to the first of these questions, the point is driven home that the real cost of the War is the sweat and sacrifice it imposes, part of which is borne by the present and part by the future. In regard to bankruptcy, the false analogy between State and individual spending is exposed, while the true object of 'warship weeks' of helping us to get warships without inflation is clearly indicated. Similarly, the importance of subordinating trade policies, when peace returns, to the over-riding aim of winning the peace, is demonstrated as well as the necessity of regarding the national resources as a sum of man-hours instead of a sum of pounds sterling, and of the imperative need for avoiding waste of men and material either by unemployment or the misdirection of resources.
In the later broadsheet, a realistic analysis is given of civilian consumption and the war effort, which suggests concisely the directions in which taxation and rationing might be further extended to promote first the war effort, but simultaneously lay the foundations for social reconstruction after the War, by giving priority to the poorest groups of the population as part of a national consumption policy to wipe out malnutrition. A much more determined attack on the 'vicious spiral' from the under-consumption end is required The essential problem here is that of subsidizing consumption among families with several children, and accordingly family endowment is now the chief weapon which must be used to combat under-consumption, though the problems of prisoners, the sick, the families of men in the Forces, and of workers receiving unusually low wages, must be considered. Much more needs to be done in respect of school-feeding services and tax relief for children before the existing services providing family endowment benefits can be regarded as adequate. Further development of the subsidized food schemes, a definite family allowance scheme, co-ordinated with existing services and for occupations where earnings are very low, and wage increases to a reasonable minimum are other proposals designed to secure a comprehensive policy and develop the maximum war effort.

\section{Illusions about the Size of the Moon}

Prof. E. G. BorIng and his associates at the Harvard Psychological Laboratory have quite recently undertaken precise measurements to determine how large the moon appears, both on the horizon and near the zenith (Sky and T'elescope, Sept.). Various observers compared the moon with an artificial moon placed at a standard distance, and the size of the artificial moon could be varied to agree with the real moon. An arrangement was made to control the orientation of the observer's head, so that the angle between direct vision and the elevation of the moon could be measured. The artificial moon, placed at a distance of $12 \mathrm{ft}$., appeared from $2^{\circ}$ to $6^{\circ}$ in diameter to people with normal vision and using both eyes. The experiments were conducted to choose between four modern theories which are associated with the physiology of the eye. The old theory that the moon is contrasted with terrestrial objects when near the horizon is ruled out by the fact that this illusion disappears when we view the horizon moon with the head upside down. The theory that the celestial sphere looks flattened overhead, the apparent distance of the moon thus varying, is also eliminated. Ames's theory alone out of the four modern theories is not finally rejected. When the eyes are raised, it has been found that the right eye tends to rotate clockwise, as viewed from the back, with respect to the left eye, and this fact may explain the moon illusion for binocular vision. It is admitted, however, that the results are not conclusive.

\section{Technical Basis of Sound Reproduction}

Aт the November meeting of the British Institution of Radio Engineers, held at the lecture hall of the Institution of Structural Engineers on November 21, Dr. L. E. C. Hughes read a paper on "The Technical Basis of Sound Reproduction". His treatment of the subject was based on his experiences as technical adviser to the Central Council for School Broadcasting, and was general in character. Dr. 
Hughes described the various degrading effects on sounds by the chamber in which they are emitted or reproduced. The final test is always a subjective one, and owing to the short memory of the ear it is necessary for comparisons between the original performance and the reproduction to be direct. This is dificult, and the method Dr. Hughes advocated was to use two separate chambers with a microphone in each to represent the listener, and to compare their outputs subjectively at the remote end of a very good quality amplifier.

Dr. Hughes explained that each letter has its own requirements in the matter of frequency range for good reproduction of speech, but he stressed the point that the final test is always an aural one in the tests conducted by the Apparatus Approval Committee of the Central Council for School Broadcasting, where non-technical audiences vote subjectively on the quality of reproduction on a scale attained entirely by experience. In the discussion which followed, doubts were expressed as to the validity of subjective tests, but Dr. Hughes stated that a completely new panel had, in duplicate tests, returned votes which were within $1-2$ per cent in agreement with the regular panel.

\section{Mickielia Timbers for Aircraft}

A sEries of leaflets has recently heen issued from the Forest Research Institute, Dehra Dun, on utilization matters. No. 17 deals with the species of Michelia of which the champaca (champ) is the most important, being fairly common in Assam and cultivated all over India for its fragrant flowers. Its true habitat is in the Eastern Himalaya, Sikkim and Assam. There are four other species of the genus in India, but they are less abundant. The timber of the five species is very similar in weight and strength and is only slightly heavier than spruce (being about $33 \mathrm{lb}$. per cubic foot as against $30 \mathrm{lb}$. for spruce) and compares very favourably with spruce in strength.

Michelia timber seasons without difficulty or degradation; it is straight grained and very easy to work both by hand and machine tools. It can, it is said, be finished to a beautiful smooth surface and is a pliant wood to handle; also it can be peeled on a rotary lathe and sliced on a slicing machine to produce excellent veneers for plywood. It is not surprising, therefore, that this timber should prove very suitable as a substitute for Sitka spruce in the manufacture of aircraft. It is stated that though supplies are limited, if the wood of these species is reserved for aircraft construction in India alone, available supplies would go some way to supplying the needs of the industry. This takes one back to a century ago when the same remarks were being made in Malabar and Tenasserim in connexion with the teak demands of the Bombay Dockyard and the Admiralty in Great Britain.

\section{Indian Woods for Battery Separators}

Leafdet No. 14 of the Utilisation Section, Forest Research Institute, Dehra Dun, deals with investigations into woods for battery separators. The battery separator is a thin sheet made of wood, ebonite or glass interposed between the positive and negative plates of an acid storage battery in order to prevent the plates from touching each other during handling or use, while at the same time allowing the ionic exchange to take place in the electrolyte. When wood is used its essential characteristics must be good permeability, freedom from volatile acids, low percentage of tannins and resinous matter, sufficient mechanical strength and resistance to chemical action of the electrolyte. The most commonly used timber has been the American Chamcecyparis lawsoniana or the Port Orford cedar. The Indian Forest Research Institute has been investigating the suitability of Indian timber for the purpose for some time past. The research work has shown that the following are suitable for use as battery separators: Adina cordifolia (haldu), Cupressus torulosa (cypress), Michelia champaca (champ or champak), and Talauma phellocarpa. The leaflet describes some of the tests carried out. As regards the Michelia it is more likely to be earmarked for aeroplane construction than battery separators, unless the wastage from the former can be utilized for the latter.

\section{Horticultural Science}

SeVEral papers upon scientific aspects of gardening have appeared in recent numbers of the Journal of the Royal Horticultural Society (vol. 67). Dr. B. A. Keen expounds his doubts of the value of hoeing except for the destruction of weeds (Part 10; Oct. 1942). This conception must now express the ideas of many workers who have considered the mechanism of water movement in soil. The experiments quoted are upon an agricultural scale, but should also have direct reference to horticulture. M. Mather publishes further work upon the effect of the moon on germination and seedling growth (Part 8; Aug. 1942). $\mathrm{He}$ again finds no consistent lunar influence, but can explain all the differences recorded for tomato and maize by the effects of temperature and light. The moon is not known to exert a great influence upon these two factors. Other experiments on growth of tomatoes are those of Dr. M. A. H. Tincker (Part 8), who finds that extracts of the vitamins in yeast do not improve growth or enhance the vitamin $B_{1}$ content of the plant.

Air Vice-Marshal A. E. Borton records (Part 10) satisfactory control of the Rhododendron bug Stephanitis rhododendri by spraying with an atomized pyrethrum wash. 'Die-back' disease of apricots makes cultivation of this crop difficult in Great Britain. H. Denham and H. Wormald show (Part 8) that the trouble is caused by the brown rot fungus Monilia cinerea (Sclerotinia laxa). It can be controlled by the removal of shoots with wilted flowers or leaves, or dead twigs. Spraying with copper carbonate washes is also mentioned.

\section{Rubber Economy in Typewriter Cylinders}

According to an article by A. R. Kemp (Bell Lab. Rec., 20, No. 12; August 1942) savings in the rubber. used for typewriter cylinders are now possible as a result of experiments recently carried on in the Bell System Chemical Laboratories. These cylinders consist of an arbor of steel or wood over which is slipped a sleeve of rubber. The rubber is vulcanized on the arbor, and then ground to the proper size and to roughen its surface so as to grip the paper firmly. With extensive use, the cylinders become hard and glazed, and no longer hold the paper securely. They have then been returned to the factory to have the old rubber removed and new rubber put in its place. It has been estimated that 